\title{
Daya Dukung Jalur Pendakian Bukit Raya Di Taman Nasional Bukit Baka Raya Kalimantan Barat
}

\author{
Toto Aryanto ${ }^{1}$, Hartuti Purnaweni ${ }^{1,2}$, Tri Retnaningsih Soeprobowati1,3 \\ ${ }^{1}$ Magister Ilmu Lingkungan Program Pascasarjana Universitas Diponegoro; email: aryantototo@yahoo.co.id \\ 2Jurusan Administrasi Publik Fakultas Ilmu Sosial dan Ilmu Politik Universitas Diponegoro \\ ${ }_{3}^{3}$ urusan Biologi, Fakultas Sains dan Matematika Universitas Diponegoro; Universitas Diponegoro
}

\begin{abstract}
ABSTRAK
Adanya upaya penyelamatan hutan dan peningkatan nilai manfaatnya, pada saat ini mulai dilakukan pemanfaatan jasa lingkungan, salah satunya melalui kegiatan pariwisata alam. Taman Nasional Bukit Baka Bukit Raya sebagai kawasan konservasi telah dimanfaatkan sebagai kegiatan pariwisata alam dan salah satunya adalah pendakian Bukit Raya. Selain memilki dampak positif, kegiatan pendakian juga memiliki dampak negatif jika tidak memperhatikan daya dukung lingkungan jalur pendakian itu sendiri. Penelitian ini bertujuan untuk menghitung daya dukung jalur pendakian Bukit Raya yang berada di Jalur kalimantan Barat. Metode yang digunakan dalam penelitian ini adalah menghitung daya dukung fisik (PCC), daya dukung riil (RCC) dan daya dukung efektif (ECC) dengan rumus yang dikembangkan oleh Cifuentes (1992). Hasil perhitungan menunjukan nilai PCC di jalur pendakian Bukit Raya adalah 200 orang per hari, RCC sebannyak 15 orang per hari dan ECC jalur pendakian Bukit Raya belum bisa dihitung sebagai akibat belum adanya desain tapak yang berpengaruh terhadap fasilitas serta penunjukan petugas pengelola secara definitif.
\end{abstract}

Kata kunci: Daya Dukung, Jalur Pendakian, Ekowisata, Taman Nasional, Bukit Raya.

\begin{abstract}
Their efforts to save the forests and increase the amount of benefit, at this time began use of environmental services, one through nature tourism activities. Bukit Baka Bukit Raya National Park as a conservation area has been used as a natural tourism activities and one of them is climbing Bukit Raya. In addition to have a positive impact, climbing activities also had a negative impact if it does not pay attention to the environmental carrying capacity climbing lane itself. This study aimed to calculate the carrying capacity Bukit Raya hiking paths that are on the West Kalimantan. The method used in this research is to calculate the physical carrying capacity (PCC), the real carrying capacity (RCC) and the effective carrying capacity (ECC) with the formula developed by Cifuentes (1992). Calculation shows the value of PCC in Bukit Raya hiking trail is 200 people per day, RCC sebannyak 15 people per day and Bukit Raya ECC climbing path can not be calculated due to the lack of tread design that affect the facility and the appointment of management personnel definitively.
\end{abstract}

Keywords: Capability, Trailhead, Ecotourism, National Park, Bukit Raya

Cara sitasi: Aryanto ,T., Purnaweni, H., dan Soeprobowati, T. R. (2016). Daya Dukung Jalur Pendakian Bukit Raya di Taman Nasional Bukit Baka Bukit Raya Kalimantan Barat. Jurnal Ilmu Lingkungan,14(2),72-76, doi:10.14710/jil.14.2.72-76

\section{PENDAHULUAN}

Dalam pemanfaatan hutan tidak terbatas pada produksi kayu dan hasil hutan bukan kayu, dapat juga dengan pemanfaatan lainnya seperti plasma nutfah dan jasa lingkungan, sehingga manfaat hutan lebih optimal. Undang-undang Nomor : 5 tahun 1990 tentang Konservasi Sumber Daya Hayati dan ekosistemnya menjelaskan taman nasional sebagai kawasan konservasi dapat dimanfaatkan untuk tujuan penelitian, ilmu pengetahuan, pendidikan, menunjang budidaya, pariwisata dan rekreasi secara serasi dan seimbang agar dapat meningkatkan kesejahteraan dan mutu kehidupan.

Taman Nasional Bukit Baka Bukit Raya sebagai salah satu dari empat taman nasional yang berada di provinsi Kalimantan Barat telah dimanfaatkan sebagai tempat untuk melakukan kegiatan pariwisata alam salah satunya yaitu kegiatan pendakian Bukit Raya. Dalam konsep Seven Summit Indonesia Puncak Bukit Raya termasuk salah satu tujuan dari tujuh puncak yang ditetapkan berdasarkan pulau besar dan gugusan pulau di Indonesia yang menggambarkan keragaman wilayah Indonesia. Untuk mencapai Puncak Bukit Raya dapat ditempuh melaui dua jalur yaitu jalur yang berada di Provinsi Kalimnatan Tengah dan Kalimanta Barat, karena aksesibilitas dan transportasi umum yang lebih mudah pengunjung lebih banyak melakukan pendakian di jalur yang berada di Kalimantan Barat.

Sebagaimana dikatakan Damanik dan Weber (2006) bahwa taman nasional memiliki potensi yang besar untuk kegiatan ekowisata ataupun pariwisata alam. Namun demikian pemanfaatan kawasan 
konservasi sebagai kegiatan pariwisata alam tentunya selain dampak positif juga akan memberikan dampak negatif terhadap lingkungan. World Tourism Organization (1993), menjelaskan bahwa pemahaman tentang ekologi dan daya dukung dibutuhkan dalam mewujudkan pariwisata yang berkelanjutan. Menurut konsep pembangunan berkelanjutan, kegiatan pariwisata dapat berlanjut jika pembangunan dapat memenuhi dan membutuhkan wisatawan dan masyarakat lokal untuk melakukan pelestarian lingkungan pada kesempatan sekarang dan waktu yang akan datang (Stubelj dan Bohanec, 2010). Ditambahkan bahwa daya dukung merupakan batas-batas dimana kehadiran wisatawan dan fasilitas pendukungnya belum atau tidak menimbulkan gangguan terhadap lingkungan fisik atau kehidupan masyarakat selain itu wisatawan juga mendapat kepuasan tanpa adanya gangguan akibat kepadatan pengunjung (Gunawan et al. 2000). Dengan demikian perlu dihitung daya dukung jalur pendakian Bukit Raya khusunya yang berada di Provinsi Kalimantan Barat agar tidak menimbulkan dampak negatif ataupun gangguan terhadap tapak dan keanekaragaman hayati yang berada di sekitar jalur pendakian. Sehingga daya dukung wisata memainkan peran penting dalam pengelolaan kawasan lindung karena dipandang sebagai sebuah sistematika, alat kebijakan strategis dalam proses perencanaan (Salerno et al., 2013).

\section{METODE PENELITIAN}

Daya Dukung Kawasan adalah kemampuan kawasan untuk menampung pengunjung dalam melakukan aktivitas pada batas maksimal agar tidak terjadi gangguan dan penurunan kualitas lingkungan yang dilakukan dengan pendekatan daya dukung fisik (PCC) dihitung berdasarkan luas kenyamanan dalam beraktivitas, daya dukung sebenarnya (RCC) dibatasi dengan tingkat toleransi kawasan dan daya dukung efektif (ECC) yang dipengaruhi oleh kapasitas manajemen.

Metode pengumpulan data terbagi menjadi metode pengumpulan data primer dan sekunder. Data primer dikumpulkan dengan metode observasi dan survey, sedangkan data sekunder dikumpulkan dengan telaah dokumen. Pengambilan data primer khususnya untuk jenis flora atau vegetasi yang berada di jalur pendakian menggunakan metode petak dalam jalur, dimana posisi plot yang ditempatkan berdasarkan ketinggian, yaitu pada ketinggian $200 \mathrm{mdpl}, 700 \mathrm{mdpl}$, $1.200 \mathrm{mdpl}, 1.700 \mathrm{mdpl}$ dan $2.200 \mathrm{mdpl}$ ke atas dengan ukuran plot $20 \mathrm{~m} \times 100 \mathrm{~m}$ pada setiap ketinggian. Untuk data fauna, dan fasilitas pendukung lainnya berdasarkan pengamatan dan wawancara. Data sekunder berisikan data mengenai iklim, jenis tanah dan kelerengan

Metode analisis yang digunakan dalam penelitian ini adalah metode kuantitatif, yaitu menghitung jumlah orang yang dapat melakukan aktivitas di lokasi pendakian Bukit Raya berdasarkan rumus yang dikembangkan Cifuentes (1992) dan dimodifikasi oleh Fandeli dan Muhammad (2009).

\section{$>$ Daya Dukung Fisik / Physical Carrying Capacity $(P C C)$} berikut :

Rumus untuk perhitungan PCC adalah sebagai

$$
P C C=A \times \frac{1}{B} \times R f
$$

dimana :

$A=$ Luas area yang digunakan sebagai objek ekowisata

$B=$ Luas kenyamanan pengunjung di objek ekowisata/m dengan tetap memperoleh kepuasan. Kebutuhan areal berwisata tiap orang untuk berenang $27 \mathrm{~m}^{2}$, piknik $65 \mathrm{~m}^{2}$ dan kemah $90 \mathrm{~m}^{2}$

$R f=$ Faktor rotasi atau jumlah pertukaran kunjungan per hari

$>$ Daya Dukung Riil / Real Carrying Capacity (RCC)

Rumus yang digunakan untuk menghitung RCC adalah sebagai berikut:

$$
\begin{gathered}
\mathrm{RCC}=P C C \times \frac{\left(100-F_{1}\right)}{100} \times \frac{\left(100-F_{2}\right)}{100} \times \ldots \\
\times \frac{(100-F n)}{100}
\end{gathered}
$$

dimana :

$F n=$ Faktor koreksi ke-n dengan data komponen ke-n

$F n=\frac{M n}{M t} \times 100 \%$

Tabel 1. Penilaian faktor koreksi

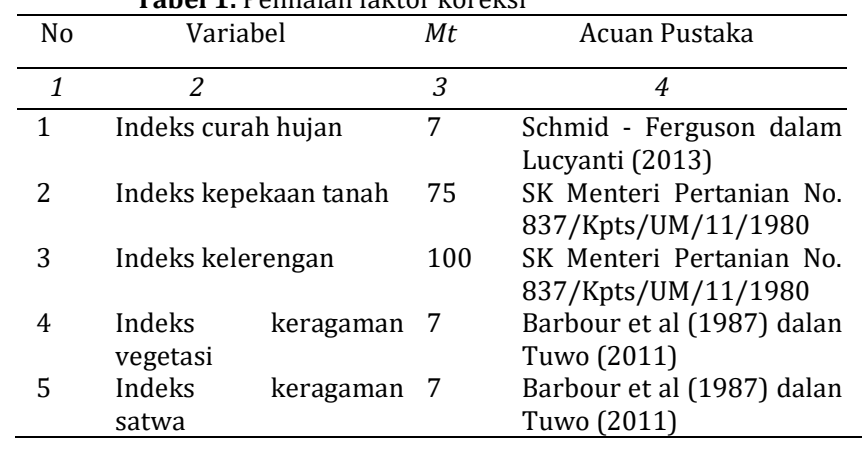

Atau menggunakan perhitungan faktor koreksi (Fn) modifikasi dari Zacarias et al (2011) dalam Lucyanti (2013):

$$
F n=1-(M n / M t)
$$

Keterangan :

$M n=$ kondisi nyata pada variabel $F n$ terhitung $M t=$ batas maksimum pada variabel $F n$ tersebut 
Penentuan $M t$ sesuai dengan faktor koreksi masing-masing yaitu seperti ditunjukkan pada Tabel 1.

$>$ Daya Dukung Efektif / Effective Carrying Capacity (ECC)

Penilaian daya dukung efektif diperoleh dari hasil perhitungan rumus sebagai berikut :

$E C C=R C C \times F M$

dimana

$F M=\frac{R n}{R t} \times 100 \%$

keterangan :

$R n=$ jumlah petugas pengelola yang ada

$R t=$ jumlah petugas pengelola yang ideal

\section{HASIL DAN PEMBAHASAN}

\subsection{Daya Dukung Fisik / Physical Carrying Capacity} (PCC)

Daya dukung fisik dimaksudkan untuk mengetahui batas maksimum dari suatu kunjungan wisata dengan mempertimbangkan kepuasan dalam aktivitas wisata dalam satuan waktu tertentu (Cifuentes,1992). Untuk mengetahui daya dukung fisik jalur pendakian Bukit Raya, data yang digunakan yaitu:

Area pada jalur pendakian Bukit Raya untuk kegiatan ekowisata $(A)=22,5 \mathrm{~km}$

- Kegiatan treking menghitung jarak antar orang, dengan asumsi jumlah dalam kelompok adalah 15 orang dan jarak ideal antar kelompok $250 \mathrm{~m}$, sehingga panjang jalur yang dibutuhkan untuk tiap orang adalah $16 \mathrm{~m}$ (Querioz et al, 2014).

- Berdasarkan hasil wawancara dengan pengunjung, rata-rata waktu yang dibutuhkan selama melakukan kegiatan di jalur pendakian Bukit Raya adalah 6,8 hari.

- Untuk kegiatan di lapangan kawasan TNBBBR buka selama tujuh hari dalam satu minggu sehingga faktor rotasi dijalur pendakian adalah satu.

Dari data di atas daya dukung fisik jalur pendakian Bukit Raya dapat dihitung dengan menggunakan rumus PCC Cifuentes (1992) (Fandeli \& Muhammad, 2009) dengan hasil:

\section{$\mathrm{PCC}=\mathrm{A} \times 1 / \mathrm{B} \times \mathrm{RF}$}

$\mathrm{PCC}=22.500 \times 1 / 16 \times 1=1.406$ orang/ minggu $\approx 200$ orang/hari

\subsection{Daya Dukung Riil ( Real Carrying Capacity/RCC)}

Faktor pembantas daya dukung efektif yang digunakan adalah faktor koreksi berupa faktor abiotik terdiri dari Curah hujan (FH), Erosivitas (FE) dan Kelerengan (FL) serta faktor biotik yaitu indeks keragaman Shanon-Wiener jenis Vegetasi pohon (FV) dan indeks keragaman jenis Shanon-Wiener Satwa liar (FS).

- Faktor pembatas dari curah hujan merupakan perbandingan antara jumlah bulan kering ( curah hujan $<60 \mathrm{~mm}$ ) dengan jumlah bulan basah ( curah hujan $>100 \mathrm{~mm}$ ). Dari data sepuluh tahun terakhir tersebut terdapat 4 bulan jumlah bulan kering dan 107 jumlah bulan basah sehingga nilai $\mathrm{Q}$ adalah sebesar 0,037. Menurut klasifikasi Schmidt dan Fergusson termasuk dalam kategori sangat basah atau tinggi. Untuk faktor koreksi curah hujan memiliki nilai 0,0053 .

- Pada jalur pendakian Bukit Raya berdasarkan peta jenis tanah Kabupaten Sintang tahun 2010 adalah latosol, memilki nilai 30 yang berarti agak peka terhadap erosi karena tanah jenis ini memiliki permeabilitas sedang sampai lambat, tekstur liat dan struktur gumpal (Arini, Prasetyo, \& Omorusdiana, 2007). Sebagai faktor koreksi, jenis tanah pada jalur pendakian mempunyai nilai 0,7

- Kondisi jalur pendakian Bukit Raya berdasarkan hasil interpolasi kontur dengan kategori datar sepanjang 3,544 km, kategori landai sepanjang 5,133 km, kategori agak curam sepanjang 6,796 km, kategori curam sepanjang 3,707 km dan kategori sangat curam sepanjang 0,265 km. Nilai rata-rata kelerengan di sepanjang jalur pendakian adalah 64,82 dan termasuk kategori agak curam dengan nilai faktor koreksi 0,3518.

- Vegetasi yang dijadikan sebagai faktor pembatas adalah vegetasi tingkat semai berdasarkan hasil inventarisasi di petak ukur pada jalur pendakian berdasarkan ketinggian. Dengan menggunakan perhitungan indeks keragaman Shannon-Wiener diketahui nilai $\mathrm{H}^{\prime}=4,17$ sehingga nilai faktor koreksi untuk vegetasi sebesar 40,43 dan termasuk kategori dengan keragaman tinggi seperti yang dinyatakan Barbour et, al., (1987) dalam Tuwo (2011) bahwa nilai $\mathrm{H}^{\prime}$ berkisar dari 0-7 dengan pembagian kriteria : (a) 0-2 kategori rendah; (b) 23 kategori sedang; (c) 3 atau lebih kategori tinggi.

- Secara keseluruhan satwa liar yang ditemukan sebanyak 16 jenis dengan jumlah individu 78 ekor. Berdasarkan data satwa tersebut nilai $\mathrm{H}^{\prime}=2,40$ dengan kategori tingkat keragaman sedang dan mempunyai nilai faktor koreksi 0,66

Tabel 2. Nilai faktor pembatas pada penentuan nilai daya dukung ekowisata di jalur pendakian Bukit Raya

\begin{tabular}{llll}
\hline $\begin{array}{l}\text { Variabel } \\
\text { Faktor } \\
\text { Koreksi }\end{array}$ & Parameter & $\begin{array}{l}\text { Nilai Indeks } \\
\text { (x 100\%) }\end{array}$ & $\begin{array}{l}\text { Nilai Faktor } \\
\text { Pengoreksi }\end{array}$ \\
\hline Biotik & $\begin{array}{l}\text { Keragaman } \\
\text { Jenis Pohon }\end{array}$ & 0,5957 & 0,4043 \\
\cline { 2 - 4 } & $\begin{array}{l}\text { Keragaman } \\
\text { Jenis Satwa }\end{array}$ & 0.3429 & 0,6571 \\
\hline Abiotik & Kelerengan & 0,6 & 0,4 \\
\cline { 2 - 4 } & $\begin{array}{l}\text { Kepekaan } \\
\text { tanah } \\
\text { terhadap erosi }\end{array}$ & 0,3 & 0,7 \\
\cline { 2 - 4 } & Curah Hujan & 0,0053 & 0,9947 \\
\hline
\end{tabular}

Sumber: Data Olahan (2015)

Daya dukung riil adalah hasil koreksi dari nilai PCC berdasarkan faktor koreksi yang telah ditentukan karena dianggap berpengaruh dalam melakukan 
kegiatan ekowisata. Nilai RCC jalur pendakian Bukit Raya adalah sebagai berikut:

$$
\begin{aligned}
R C C=P C C & \times \frac{(100-F H)}{100} \times \frac{(100-F E)}{100} \times \ldots \\
\times & \frac{(100-F n)}{100} \\
R C C=1.406 & \times 0,4043 \times 0,6571 \times 0,40 \times 0,70 \\
& \times 0,9947
\end{aligned}
$$

$R C C=104,03$

$$
R C C \approx 104 \text { orang } / \text { minggu }=15 \text { orang/ hari }
$$

Hasil perhitungan RCC jumlah orang yang dapat berkunjung yaitu sebanyak 104 orang per minggu atau sebanyak 15 orang/ hari dan jumlah pengunjung yang melakukan aktivitas di jalur pendakian pada tahun 2015 belum melampaui jumlah RCC yaitu baru sebanyak 30 orang per September 2015. Dalam mengukur RCC, faktor-faktor koreksi diperoleh dari hasil pertimbangan keadaan lingkungan, biofisik dan sosial dan ini terkai erat dengan keadaan setiap lokasi dan kegiatannya (Queiroz et al., 2014). Metodologi RCC ini dimungkinkan mengidentifikasi dampak pengunjung yang mempengaruhi faktor fisik untuk pengelolaan kawasan lindung. Dalam skala kecil bukan total RCC yang dihitung melainkan peringkat RCC terendah adalah salah satu yang membatasi operasi pariwisata (Monteiro \& Silva, 2012).

\subsection{Daya Dukung Efektif (Effective Carrying Capacity/ECC)}

Daya dukung efektif terkait jumlah dan kapasitas sumber daya manusia dalam memberikan pelayanan terhadap pengunjung sehingga menurut Luciyanti (2013) nilai daya dukung efektif (Effective Carrying Capacity/ ECC) adalah jumlah maksimum pengunjung yang diterima pada suatu objek wisata untuk kepentingan umum, yang diperoleh dari nilai daya dukung riil (ECC) yang dikaitkan dengan kapasitas manajemen pengelola objek wisata dalam memberikan pelayanan yang prima (service excellent) terhadap pengunjung objek ekowisata.

Untuk jalur pendakian Bukit Raya belum bisa dihitung daya dukung efektifnya dikarenakan jumlah personil Resort Rantau Malam sebanyak empat orang yang terdiri dari satu orang Polhut, dua orang Tenaga Pengaman Hutan Lainnya (TPHL) dan satu orang tenaga kontrak tidak diperuntukan khusus dalam pengelolaan jalur pendakian Bukit Raya, karena personil-personil tersebut sewaktu-waktu dapat diperbantukan pada wilayah kerja resort lainnya dalam pelaksanaan tugas pengamanan kawasan hutan.

Hasil perhitungan jumlah pengunjung yang dapat diterima pada jalur pendakian Bukit Raya hanya sebatas pada perhitungan nilai daya dukung riil, Menurut Queiroz et al (2014) perlu segera dihitung nilai daya dukung efektif karena keadaan yang demikian merupakan merupakan titik lemah dalam kapasitas jalur pendakian Bukit Raya sebagai akibat kelangkaan sumber daya manusia sehingga tidak mungkin optimal dalam kinerja.

Kegiatan ekowisata berdasarkan pengertiannya dapat memberikan solusi dalam pengelolaan kawasan konservasi karena dapat membantu dalam pembiayaan kegiatan konservasi. Akan tetapi kegiatan ekowisata juga akan memberikan dampak negatif terhadap lingkungannya dikarenakan aktivitas yang dilakukan akan berpengaruh terhadap kondisi fisik, vegetasi dan satwa yang berada lokasi tersebut sehingga dalam pengembangan suatu kawasan untuk kegiatan ekowisata harus dikaji daya dukungnya untuk mengurangi gangguan yang ditimbulkan (Purnomo, Sulistyantara, \& Gunawan, 2013).

\section{KESIMPULAN DAN SARAN}

Hasil perhitungan jalur pendakian Bukit Raya memiliki nilai PCC $=200$ orang/ hari, RCC $=15$ orang/ hari, kondisi demikian jumlah pengunjung yang melakukan kegiatan di jalur pendakian Bukit Raya Provinsi Kalimantan Barat belum terlampaui. Namun nilai ECC belum dapat dihitung karena keterbatasan dalam faktor manajemen dalam hal ini sumber daya manusia dan sarana dan prasarana di jalur pendakian Bukit Raya. Belum tersedianya sumber daya manusia baik dalam jumlah dan kualitas akan mempengaruhi keberlanjutan kegiatan ekowisata di jalur pendakian Bukit Raya

Keterbatasan sarana dan prasarana disebabkan belum adanya desain tapak jalur pendakian Bukit Raya sehingga pengaturan dan penempatan fasilitas untuk menunjang kegiatan di jalur pendakian belum dapat dilakukan, sehingga perlu segera untuk merancang desain tapak serta peningkatan promosi jalur pendakian terkait daya dukung yang belum terlampaui.

\section{DAFTAR PUSTAKA}

Arini, D. I. D., Prasetyo, L. B., \& Omorusdiana. (2007). Aplikasi Sistem Informasi Geografis (Sig) Dan Penginderaan Jauh Untuk Model Hidrologi Answers Dalam Memperdeksi Erosi Dan Sedimentasi (Studi Kasus : Dta Cipopokol Sub Das Cisadane Hulu Kabupaten Bogor). Media Konservasi, XII, Nomor, 1-10.

Damanik, J. dan H. F. Weber. (2006). Perencanaan Ekowisata dari Teori ke Aplikasi. Penerbit Andi. Yogyakarta.

Fandeli, Chafid dan Muhammad. (2009). Prinsip-Prinsip Dasar Mengkonservasi Landskap. Gadjah Mada University Press. Yogyakarta.

Gunawan, P, M. Nasikun. Khodiyat. Et al. (2000). Agenda 21: Agenda Pariwisata Untuk Pengembangan Kualitas Hidup Secara Berkelanjutan. Penerbit: Proyek agenda 21 Sektoral Kerjasama Menteri Negara Lingkungan Hidup Dengan UNDP. Jakarta.

Lucyanti, S. (2013). Strategi Pengembangan Objek Wisata Alam Bumi Perkemahan Palutungan Berdasarkan Pendekatan Daya Dukung Lingkungan di Taman Nasional Gunung Ciremai. Tesis. Program Pascasarjana Universitas Diponegoro. Semarang. 1$161 \mathrm{pp}$.

Monteiro, L., \& Silva, C. P. da. (2012). Assessing carrying capacity in protected areas trails: The Formosinho Trail - Arrábida natural Park (Portugal)., Proceedings Monitoring and Management of Visitors in Recreational and Protected Areas (pp. 102-103). Stockholm, Sweden.

Purnomo, H., Sulistyantara, B. dan Gunawan A. Peluang Usaha Ekowisata Di Kawasan Cagar Alam Pulau Sempu Jawa Timur. 
Jurnal Penelitian Sosial dan Ekonomi Kehutanan Vol. 10 No. 4, Desember 2013, Hal 247-263.

Queiroz, R. E.,Ventura, M. A., Guerreiro, J. A., Cunha, R.T. (2014). Carrying capacity of hiking trails in Natura 2000 sites: a case study from North. Atlantic Islands (Azores, Portugal). Journal of Integrated Coastal Zone Management. 14(2):233-242 (2014) DOI:10.5894/rgci471.

Salerno, F., Viviano, G., Manfredi, E. C., et al. (2013). Multiple Carrying Capacities from a management-oriented perspective to operationalize sustainable tourism in protected areas. Journal of Environmental Management, 128, 116-25. doi:10.1016/j.jenvman.2013.04.043

Stubelj, M., dan Bohanec, M. (2010). Towards the ecotourism: A decision support model for the assessment of sustainability of mountain huts in the Alps. Journal of Environmental Management, 91(12), 2554-2564. doi:10.1016/j.jenvman.2010.07.006

Undang Undang RI Nomor : 5 . Tahun 1990. Tentang Konservasi Sumber Daya Alam Hayati dan Ekosistemnya. 